\title{
Proteomic Analysis of Wort with Focus on Potential Dif- ferentiation of Malting Barley Cultivars
}

\author{
Martin Dušek ${ }^{1 *}$, Michaela Ščigelová2, Vladimíra Jandovskáa and Jana Olšovská ${ }^{1}$ \\ 1 Research Institute of Brewing and Malting, Lípová 511/15, \\ 12000 Prague, Czech Republic \\ 2 Thermo Fisher Scientific, Hanna-Kunath-Str. 11, \\ 28199 Bremen, Germany \\ 3 Faculty of Science, Charles University, Albertov 6, \\ 12800 Prague, Czech Republic \\ *correspondence e-mail: dusek@beerresearch.cz
}

\begin{abstract}
We analyzed the profile of malt proteins in boiled wort preparations using liquid chromatography coupled to high resolution mass spectrometry. Proteins detected in 9 different malt barley cultivars were identified. We probed proteins for post-translational modifications, namely glycation. Differential analysis of the wort proteomes provided insight into the effect of malting barley cultivar as well as location of cultivation. The results suggest that proteome analysis of wort samples could allow for identification/classification of malting barley cultivars used in wort production.
\end{abstract}

Keywords: barley, malt, cultivars differentiation, proteomics, LC-MS

\section{Introduction}

Barley (Hordeum vulgare L.) is the most common grain used in brewing industry, being popular for its flavor and nutritional properties. To make beer, firstly, barley is turned into malt during the technological process called malting. A mashing step follows, when various compounds, including sugar, dextrins, proteins, minerals, and phenolic compounds, are extracted. The resulting liquid is thereafter referred to as wort.

During the process of malting and brewing, the enzymes ( $\alpha$-amylase, $\beta$-amylase) are developed which degrade starch into various types of sugar: glucose, maltose, maltotriose, and higher sugars called maltodextrines. Also proteins undergo a conversion during malting and mashing steps; about $40 \%$ of the total grain protein becomes so called soluble protein, which represents about $4-6 \%$ of the total malt (by weight). Soluble protein (a mixture of proteins, peptides, and amino acids) is important for yeast growth during fermentation and for malt/beer color development.

Multiple aspects are considered when selecting a malting barley variety for beer production. Most brew- ers rely on brewing institutes or associations to approve and recommend barley varieties for malting based upon their brewing properties. There is a need for a quick and accurate method enabling a reliable discrimination of various cultivars. An approach based on identifying proteins and their glycation state using mass spectrometry has been reported as promising (Petry-Podgórska et al., 2010; Šalplachta and Bobálová, 2008). In this study, we undertook the proteome analysis of wort prepared from different European-grown varieties of 2-row malting barley. Our primary interest was to identify barley proteins in wort samples using liquid chromatography coupled to high resolution mass spectrometry. We paid special attention to proteins and their modifications deemed important in the brewing process. Further, we performed differential analysis, considering protein identifications as well as their respective abundances, of several sets of wort samples. The data was evaluated for a statistically significant difference between wort preparations originating from different malting barley cultivars. Similar comparison was also performed for wort samples ob- 
tained from the same malting barley cultivar, however, grown at different locations.

\section{Materials and methods}

\subsection{Wort sample preparation}

The proteomic profile of barley was studied for a set of six cultivars of two-row spring barley: Bojos, Francin, Laudis 550, Malz, Pioneer, and Sunshine; and three cultivars of two-row winter barley: Ariane, Tepee, and Wintmalt; all harvested in the Czech Republic at the locality Polná.

Differential analysis of malting barley cultivars was performed on a set of four two-row spring barley cultivars, all originated from the Czech Republic, analyzed in 5 technical replicates: Bojos, Laudis 550, Petrus, and Tolar. The analysis was further extended to include 18 different malting barley varieties (4 technical replicates each), all grown in the Czech Republic: Gesine, Vendela, Xanadu, Sunshine, Kampa, Wintmalt, Irina, Bojos, Ariane, Francin, Malz, Petrus, Laudis 550, Tolar, Blaník, Sebastian, Kangoo, and Sanette.

For the study investigating a potential impact of environmental conditions associated with the production locality of barley on wort sample proteome, the differential analysis was carried out with Laudis malting barley grown at four different locations: Czech Republic, Germany, the Netherlands and Slovakia.

Laboratory malts were prepared from barley by a standard procedure used at the Research Institute of Brewing and Malting for evaluation of barley varieties: steeping for 72 hours at $14{ }^{\circ} \mathrm{C}$ with $\mathrm{CO}_{2}$ exhaustion, water $1^{\text {st }}$ day 5 hours, $2^{\text {nd }}$ day 4 hours, and $3^{\text {rd }}$ day 3 hours. Total germination time was $72 \mathrm{~h}$ at $14{ }^{\circ} \mathrm{C}$. Pre-drying was performed at $55^{\circ} \mathrm{C}$, followed by 4 hours of kilning at $80^{\circ} \mathrm{C}$.

Laboratory wort used for the isolation of wort proteins was prepared according to the EBC congress mash procedure 4.5.1 malt section (EBC Analysis Committee, 1998). Wort proteins were precipitated by adding ice cold acetone $(800 \mu \mathrm{L})$ to a tube containing $200 \mu \mathrm{L}$ of wort. The solution was mixed and incubated for 90 minutes at $-20^{\circ} \mathrm{C}$. The precipitated proteins were collected by centrifugation at $13.000 \mathrm{x}$ g for 10 minutes. The supernatant was carefully removed, and the protein pellet inside the uncapped tube was left for 30 minutes at room temperature to allow for acetone to evaporate. The protein pellet was re-dissolved by adding $40 \mu \mathrm{L}$ of $50 \mathrm{mM}$ ammonium bicarbonate buffer (pH 7.8). After reduction (dithiothreitol) and alkylation (iodoacetamide), $10 \mu \mathrm{L}$ of modified porcine sequencing-grade modified trypsin $(0.1 \mu \mathrm{g} / \mu \mathrm{L}$; Promega, Madison, WI, USA) was added, and the samples were incubated at $37^{\circ} \mathrm{C}$ for $16 \mathrm{~h}$. The resulting peptide digest $(14 \mu \mathrm{L})$ was pipetted into a new tube and acidified by adding $16 \mu \mathrm{L}$ of aqueous solution containing $0.5 \%$ formic acid and $25 \%$ acetonitrile $(\mathrm{v} / \mathrm{v})$. The final volume in the tube was adjusted to $50 \mu \mathrm{L}$ with ultrapure water and analyzed by liquid chromatography coupled to mass spectrometry.

\subsection{Liquid Chromatography Mass Spectrometry}

Mass spectrometry analyses used in this study were done on the $Q$ Exactive hybrid quadrupole-Orbitrap mass spectrometer (Thermo Fisher Scientific, Waltham, MA, USA) equipped with the Thermo Scientific UltiMate 3000 HPLC system. For each run, $5 \mu \mathrm{L}$ of the digest was injected on a $2.1 \times 150 \mathrm{~mm}$ reverse phase Discovery C18 column (Supelco, Bellefonte, PA, USA) with $5 \mu \mathrm{m}$ particles kept at $35^{\circ} \mathrm{C}$, at flow rate $200 \mu \mathrm{L} / \mathrm{min}$. Chromatography solvents were water (A) and acetonitrile (B), both with $0.1 \%(\mathrm{v} / \mathrm{v})$ formic acid. Peptides were eluted from the column with $5 \%$ of solvent B for $5 \mathrm{~min}$, followed by linear gradients: first to $50 \%$ B at $65 \mathrm{~min}$, then to $90 \% \mathrm{~B}$ at $70 \mathrm{~min}$. The column was held at this solvent composition for another 10 min before re-equilibrating at 5\% B.

The tandem mass spectra (MS/MS) of peptides eluting from the column were acquired in data-dependent scanning mode with one full scan followed by MS/MS scans of the top 12 most intense precursors, dynamically excluding previously selected precursors for a period of $10 \mathrm{~s}$. The peptides were being selected from the range $300-1750 \mathrm{~m} / \mathrm{z}$, the resolving power was set to 70,000 full width at half peak height maximum (FWHM) at $m / z$ 200 for MS scans, AGC target was set to 3 e 6 counts. The data dependent MS/MS scans were performed at resolving power 17,500 FWHM at $m / z$ 200, with an AGC target of $1 \mathrm{e} 5$ counts. The maximum injection time was set to $45 \mathrm{~ms}$, isolation width was $3.0 \mathrm{~m} / \mathrm{z}$, normalized collision energy $28 \%$, while automatically excluding isotopes, 'unknown' charge states, and charge states higher than 5 . Peptide match parameter was set to 'preferred'.

\subsection{Data Processing - Protein Identification}

Proteome Discoverer 2.1 software (Thermo Fisher Scientific) was used for peptide and protein identification via a database search (Sequest HT search engine) against database combining Hordeum vulgare proteins (SwissProt taxonomy ID 4513, incl. subcategories; 364 sequences) and common contaminants (298 sequences), considering semi-tryptic specificity (retained peptide $C$-terminus), allowing for up to two missed tryptic cleavage sites, precursor mass tolerance $10 \mathrm{ppm}$, fragment mass tolerance $0.02 \mathrm{Da}$. Carbamidomethylation of Cys was set as a static modification, while carbamidomethylation of His, Lys, and peptide $\mathrm{N}$-terminus were set as dynamic modifications. The latter modifications were included based on results 
from Preview software (Protein Metrics, Cupertino, CA, USA), being indicative of sample over-alkylation. Proteins identified with at least one highly confident (FDR max. 1\%) peptide were included in a 'target' database subsequently used for a two-step searching of individual raw files (total 112 protein sequences; Figure 1). This two-step search procedure contained the repetition of the search routine described above followed by the second round of searching against the 'target' database considering an extended selection of dynamic modifications (oxidation of Met, formation of pyroglutamate on peptide $N$-terminal Gln, and glycosylation of Lys). The benefit of employing such an iterative search workflow is that the results from both/multiple steps are pooled and displayed in a single file.

Figure 1 Outline of an iterative workflow used in the study. Note the two Sequest HT search nodes deployed in the workflow.

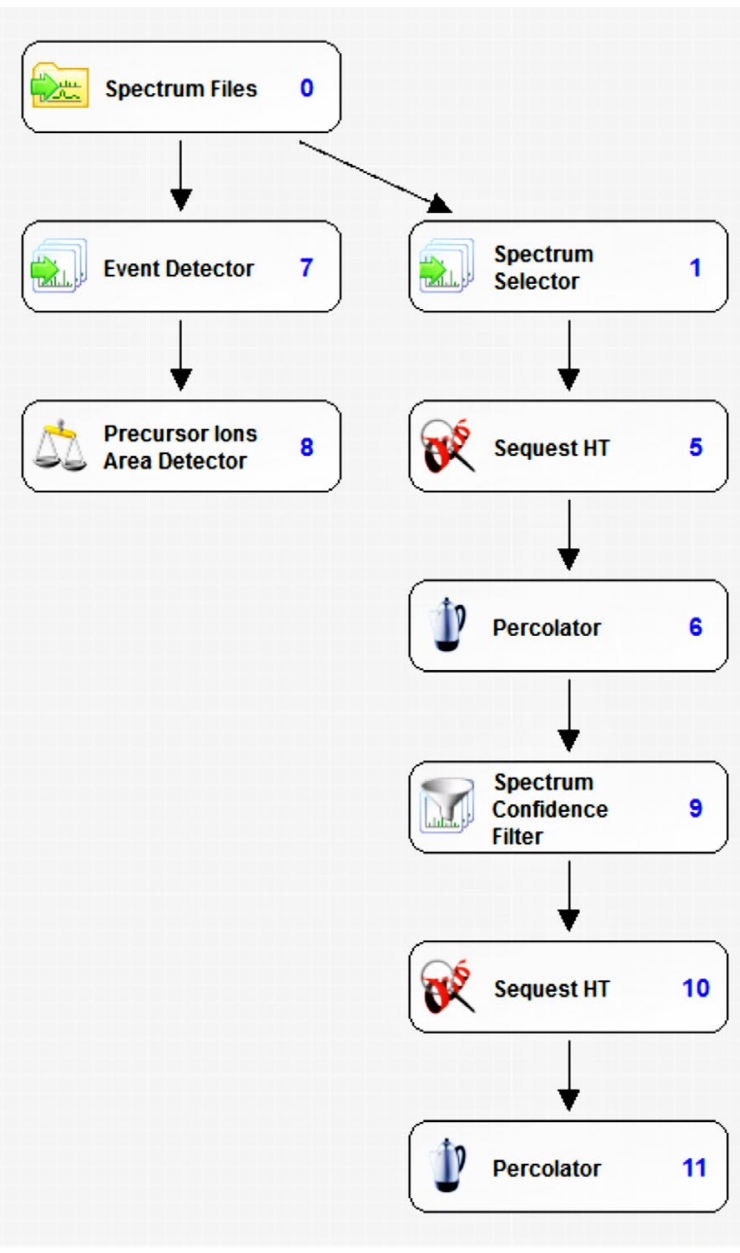

\subsection{Data Processing - Differential Analysis}

Data was processed with SIEVE 2.2 SP2 software (Thermo Fisher Scientific) which allowed to compare wort samples prepared with differing malting barley. SIEVE software aligned the MS spectra over time from different experimental conditions and then determined features in the data $(\mathrm{m} / \mathrm{z}$ and retention time pairs) that differed across the sample groups studied. The following parameters were set for retention time alignment and peak detection needed for abundance calculations: retention time range $2-45 \mathrm{~min}, \mathrm{~m} / \mathrm{z}$ range $375-1750$, peak width max. 2.5 min, peak $\mathrm{m} / \mathrm{z}$ tolerance $10 \mathrm{ppm}$, peak intensity threshold 50000 . Only proteins detected by at least two highly confident peptides (see above) were considered for statistical evaluation of the abundance change (standard t-test) where p-value smaller than 0.05 was considered statistically significant.

\section{Results and Discussion}

Wort contains the sugars, the most important being maltose and maltotriose, that will be fermented by the brewing yeast to produce alcohol. Wort also contains crucial amino acids to provide nitrogen to the yeast as well as more complex proteins contributing to beer head retention and flavour (Fix, 1999). Individual proteins critically impact the quality of the final product. While certain proteins are associated with such desirable features as foam formation, foam stabilization, and mouth feel of beer, others are implicated in haze formation, and have to be precipitated to guarantee the final product stability (Evans and Sheehan, 2002).

Protein analysis technique we employed in this study was liquid chromatography coupled to high resolution mass spectrometry. The identification relies on matching tandem mass spectra of peptides, generated by tryptic digestion of constituent proteins, to predicted spectra derived based on amino acid sequences of known barley proteins. Our proteome analysis identified over 30 protein groups in wort samples, based on about 200 confidently identified peptides (Table 1).

Table 1 Number of protein and peptide identifications in wort samples prepared using different malting barley cultivars

\begin{tabular}{|c|c|c|}
\hline Cultivar & Proteins $(\mathrm{n})$ & Peptides $(\mathrm{n})$ \\
\hline Ariane & 28 & 190 \\
\hline Bojos & 33 & 227 \\
\hline Francin & 29 & 201 \\
\hline Laudis 550 & 31 & 213 \\
\hline Pioneer & 33 & 222 \\
\hline Sunshine & 34 & 236 \\
\hline Tepee & 32 & 220 \\
\hline Wintmalt & 35 & 217 \\
\hline
\end{tabular}


The most abundant proteins identified in wort samples belonged to beta- and gamma-hordeins (30$35 \mathrm{kDa}$ ), and serpins (43 kDa). Together with glyceraldehyde-3-phosphate dehydrogenase (33 kDa) these proteins contribute to the major protein band detected by gel electrophoresis (Figure 2). The next prominent band in the gel analysis (15 kDa) corresponds to alpha-amylase/ trypsin inhibitor proteins, also detected in high abundance in our wort samples. The quantitative over-representation of these proteins here is in agreement with published reports (Benkovská et al., 2011; Šalplachta and Bobálová, 2009; Chmelík et al., 2002).

Our in-depth probe into protein modifications uncovered many peptide candidates carrying hexose on lysine residues. Glycated proteins are implicated in beer properties such as foam formation and retention. These derivatives are believed to be products of Maillard reaction, a chemical reaction between amino acids and reducing sugars that gives browned food its distinctive flavor. The most favorable process phase conditions for the formation of Maillard products during brewing process occur during malt kilning, owing to the low moisture content. Maillard browning reactions also take place in the kettle during wort boiling (Ames, 1988). The extent to which the boiling process itself contributes to the generation of these compounds in final wort preparations is a subject of ongoing research (Cordova, 2019).
Figure 2 Coomassie-stained SDS-PAGE (10\% acrylamide) of water soluble proteins extracted from 8 cultivars of malting barley: Wintmalt (1), Laudis 550 (2), Sunshine (3), Bojos (4), Pioneer (5), Tepee (6), Francin (7), Ariane (8).

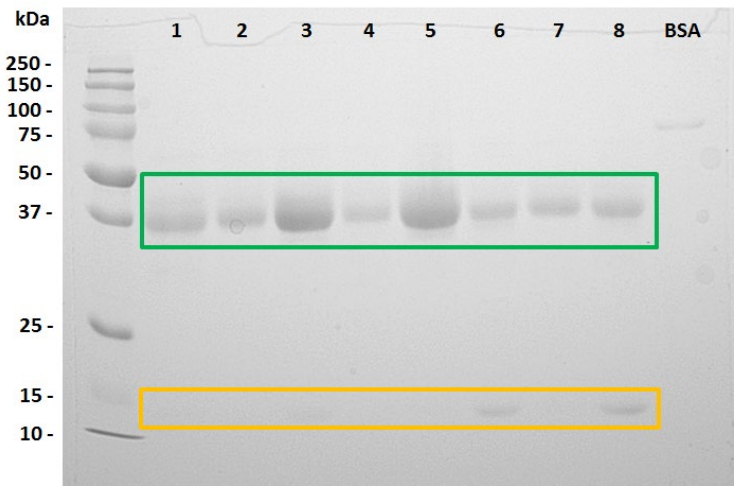

Figure 3 shows an example of glycated peptide MKPCLTYVQGGPGPSGECCNGVR from non-specific lipid-transfer protein 1 (P07597), detected with a hexose modification on lysine residue $(\mathrm{K}$ in position 2 of the peptide). Internal lysine residue signals a missed tryptic cleavage, a likely corollary of the site being shielded from the enzyme by the sugar residue; thus further corroborating the confidence of peptide identification.

One would expect the protein profile in final wort preparations to differ depending on the malting barley cultivar and the malting process used. In order to assess the potential impact malting barley cultivars, we

Figure 3 Annotated MS/MS spectrum of peptide MKPCLTYVQGGPGPSGECCNGVR from non-specific lipid-transfer protein 1 (P07597) detected at retention time 17.2051 min as charge state +4 , monoisotopic $\mathrm{m} / \mathrm{z}$ 686.55334 Da (mass deviation from theoretical mass $-0.68 \mathrm{mmu} /-0.99 \mathrm{ppm})$. The peptide carries hexose modification on lysine $(K)$ in position 2 , in addition to carbamidomethylation on the initial methionine residue.

Bojos_A.raw \#8251 RT: $16.9929 \mathrm{~min}$

FTMS, 686.8033@hcd28.00, $z=+4$, Mono $m / z=686.55255 \mathrm{Da}, \mathrm{MH}+=2743.18838 \mathrm{Da}$, Match Tol $=0.02 \mathrm{Da}$

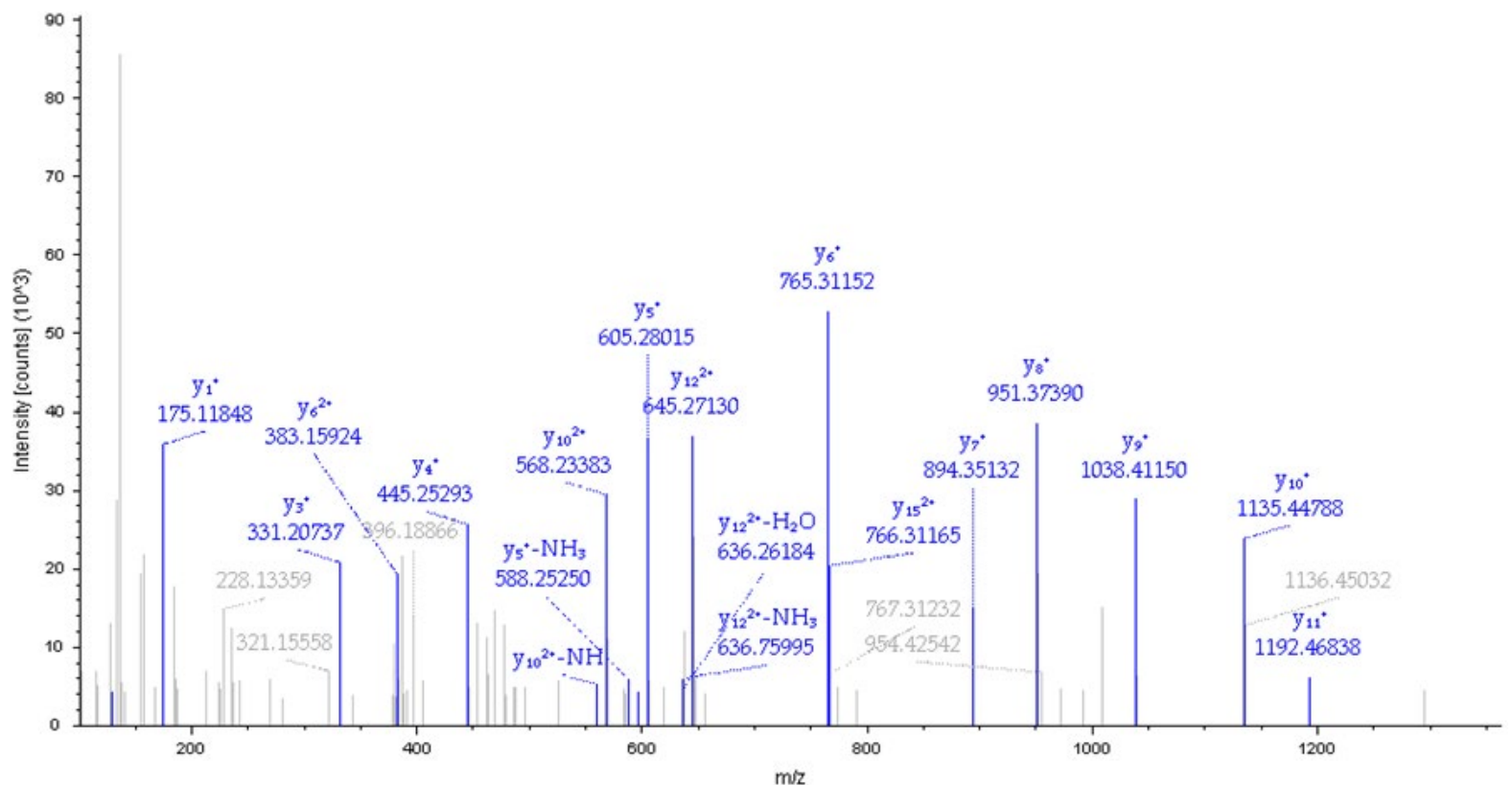


performed statistical analysis considering the kind and relative abundances of wort proteins detected in the samples. The analyses outcomes confirmed that statistically significant differences exist among wort preparations obtained from different malting barley variants.

First, we analyzed wort prepared from four different malt cultivars produced in the Czech Republic. Each sample has been analyzed in five technical replicates to ensure a robust statistical outcome. Figure 4 shows the principal component analysis (PCA) plot of wort preparations obtained with Bojos, Laudis, Petrus, and Tolar malting barley cultivars. Very clear separation of sample groups based on malting barley used can be seen.

Next, we extended the differential analysis to wort preparations derived from eighteen different malting barley varieties, all grown in the Czech Republic. The PCA plot based on quadruplicate analysis of wort preparations is shown in Figure 5. The samples strongly group according to malting barley cultivar used, suggesting that proteome analysis of wort samples can be potentially used as a tool for identification/classification of malting barley variants used in the brewing process. Interestingly, sample groups prepared with Laudis 550 (Czech Republic) and Sanette (United Kingdom) cultivars overlap in the graph. Their grouping on the PCA plot might be due to their genetic similarity but we have no data to support such a claim.
Figure 4 Principal component analysis (PCA) plot of wort preparations obtained with Bojos, Laudis, Petrus, and Tolar malting barley cultivars, all grown in the Czech Republic. Analysis based on five technical replicates for each sample.

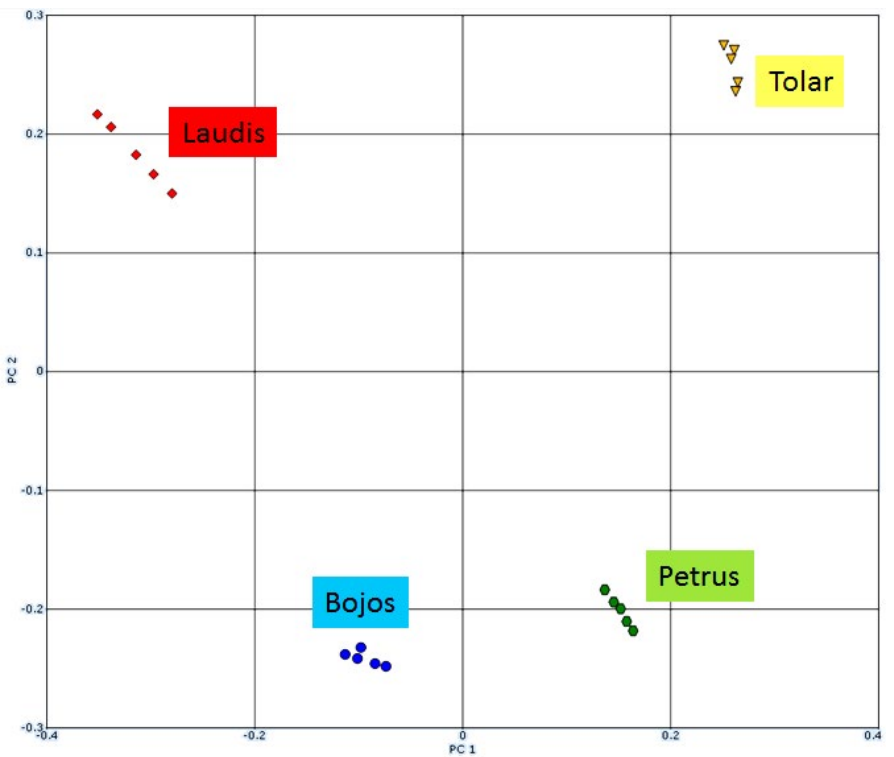

The Research Institute of Brewing and Malting has a rich bank of malting barley samples. This provided us with an opportunity to compare the proteomes of wort samples prepared with malt derived from an identical cultivar grown, however, at different locations. We were interested whether varied environmental factors (sometimes referred to as 'terroir') would leave their imprint on the proteome of final wort preparations. Differential

Figure 5 The PCA plot of wort preparations obtained with eighteen malting barley cultivars, all grown in the Czech Republic: Gesine (1), Vendela (2), Xanadu (3), Sunshine (4), Kampa (5), Wintmalt (6), Irina (7), Bojos (8), Ariane (9), Francin (10), Malz (11), Petrus (12), Laudis 550 (13), Tolar (14), Blaník (15), Sebastian (16), Kangoo (17), Sanette (18). Results based on four repetitive analyses.

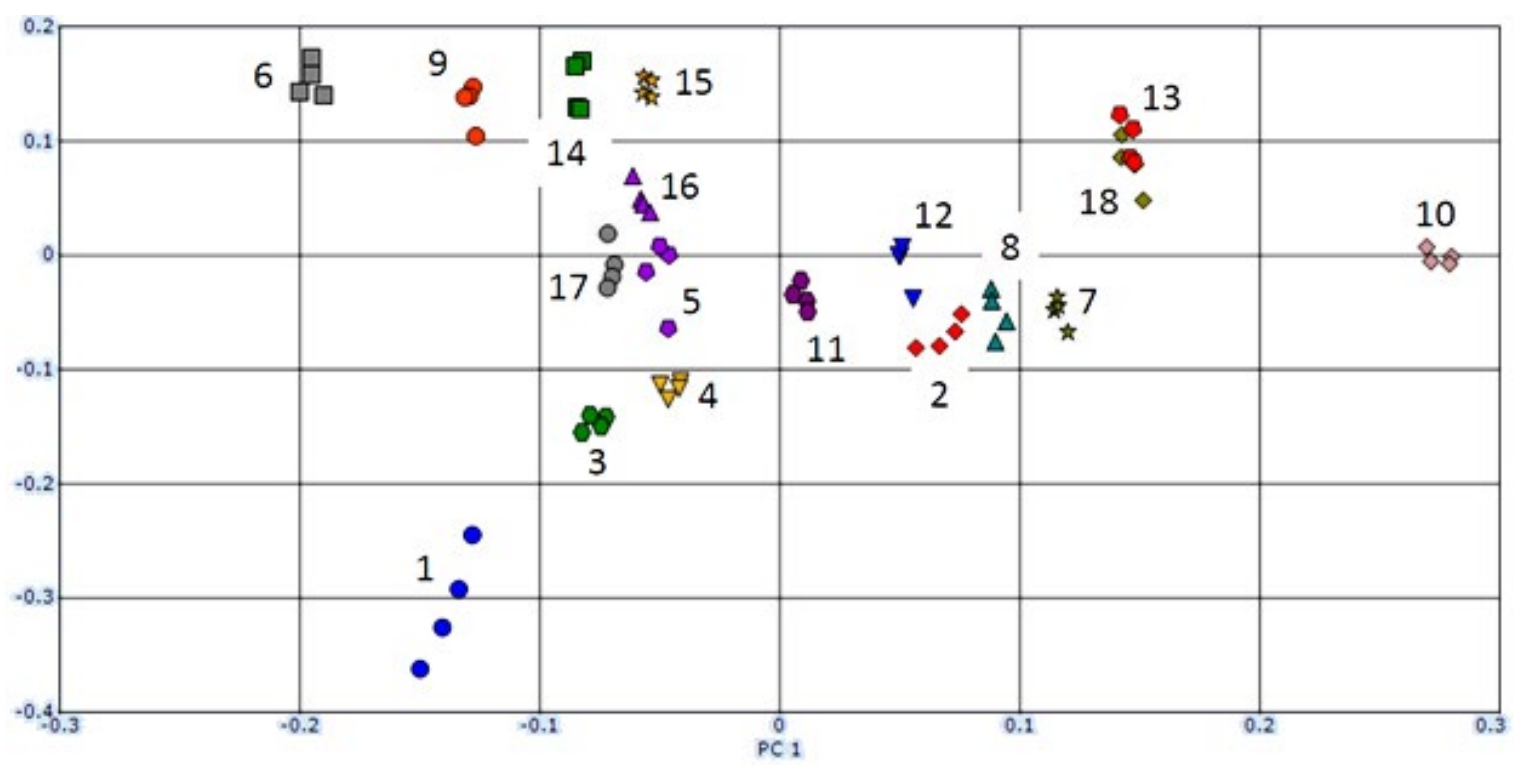


analysis of wort samples obtained with Laudis malting barley variety grown in the Czech Republic, The Netherlands, Slovakia and Germany showed that there were statistically significant differences (Figure 6). This indicated that the environmental conditions associated with different localities impacted the proteome of wort samples in discernible manner.

Statistically significant differences can be detected among wort preparations from various malting barley cultivars. Interestingly, significant differences among wort products were also observed when using a genetically identical malting barley cultivar produced in distinct European localities.

\section{Conclusion}

Barley proteins identified by liquid chromatography coupled to high resolution mass spectrometry showed relatively high amounts of hordein and amylase inhibitor proteins, supporting the gel analysis outcome. Detection of hordeins is of particular interest for the analyses of gluten-free beers. We were also able to identified glycated forms of barley proteins in our experiments, a modification associated with such important beer properties as foam formation and retention. The results of differential analyses indicate that both the cultivar and the environmental factors (terroir) have a statistically significant impact on the final wort proteome.

\section{Author Contributions}

M.D. conceived of the presented idea. M.D. and V.J. carried out the experiments. M.S. processed raw data and inter-

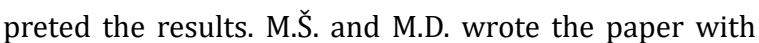
input from all authors.

\section{Acknowledgement}

This study was supported by the project TE02000177 'Centre for Innovative Use and Strengthening of Competitiveness of Czech Brewery Raw Materials and Products' of the Technology Agency of the Czech Republic; institutional support MZE-R01918 from Ministry of Agriculture of the Czech Republic; and Charles University within the project SVV260440. igure 6 The PCA plot obtained for wort preparations prepared with Laudis malting barley grown at four different European locations. Results based on five repetitive analyses.

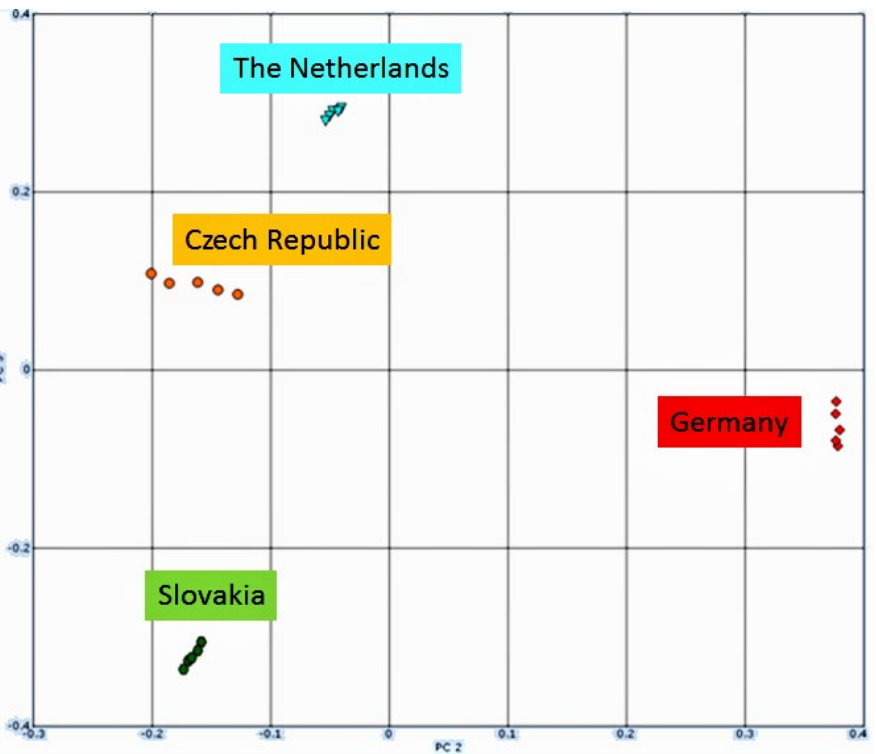

\section{References}

Ames, J. M., 1988: The Maillard browning reaction-an update. Chem. Ind., 17: 558-561.

Benkovská, D., Flodrová, D., Psota, V., Bobálová, J., 2011: Influence of the brewing process on the barley protein profile. Kvasny Prum., 57(78): 260-265.

Chmelík, J., Řehulka, P., Střelcová, M., Kubáň, V., Mayrhofer, C., Allmaier, G., 2002: Proteomic analysis of different extracts from barley grains. Rost. Vyroba, 48(6): 261-264.

Cordova, K. Personal communication.

EBC Analysis Committee, 1998: Analytica-EBC. Verlag Hans Carl Getränke-Fachverlag, Nürnberg. ISBN 3418007597.

Evans, E. D., Sheehan, M. C., 2002: Don't be fobbed off: The substance of beer foam - A review. J. Amer. Soc. Brew. Chem., 60(2): 47-57.

Fix, G., 1999: Principles of Brewing Science: A Study of Serious Brewing Issues. Brewers Association, Boulder, CO. ISBN 0937381748.

Petry-Podgórska, I., Žídková, J., Flodrová, D., Bobálová, J., 2010: 2D-HPLC and MALDI-TOF/TOF analysis of barley proteins glycated during brewing. J. Chromatogr. B Analyt. Technol. Biomed. Life Sci., 878(30), 3143-3148.

Šalplachta, J., Bobálová, J., 2009: MALDI-TOF mass spectrometry of hordeins: rapid approach for identification of malting barley varieties. J. Mass Spectrom., 44(9), 1287-1292. 